\title{
Effect of Test Temperature on Fatigue of Shot Peened Magnesium Alloys
}

\author{
Jens Wendt, André Ketzmer and Lothar Wagner
}

Chair of Physical Metallurgy and Materials Technology, Technical University of Brandenburg at Cottbus, Cottbus, Germany

\section{$1 \quad$ Abstract}

The effect of test temperature ranging from -25 to $+50^{\circ} \mathrm{C}$ on mechanical properties of the highstrength wrought magnesium alloy AZ80 was evaluated. While yield stress and tensile strength within this temperature range continuously increased with decreasing temperature, the $10^{7} \mathrm{cy}$ cles notch fatigue strength in fully reversed loading exhibited a marked minimum at $T=0{ }^{\circ} \mathrm{C}$. Shot peening was found to improve the fatigue strength at all tested temperatures.

\section{Introduction}

High-strength wrought magnesium alloys are considered for substituting steels and even aluminum alloys as suspension components in future automobiles due to their high strength to weight ratio [1-3]. For this application, good HCF performance of notched components is one of the most important requirements. Since notched components respond particularly well to a shot peening treatment owing to the interaction of the notch root stress field with the process-induced residual compressive stresses [4, 5], the effect of shot peening on the fatigue performance using a wide variation in Almen intensities was studied. In contrast to applications in transmission gear housings and engine blocks, where mechanical properties at elevated $\left(120-150{ }^{\circ} \mathrm{C}\right)$ temperatures are important, typical temperatures for suspension parts in automobiles are in the range -25 to $+50^{\circ} \mathrm{C}$.

\section{Experimental}

The wrought magnesium alloy AZ80 (nominal composition in weight percent: $8 \mathrm{Al}, 0.5 \mathrm{Zn}, 0.2$ Mn, balance: $\mathrm{Mg}$ ) was received as extrusion from Otto Fuchs Metallwerke, Mei-nerzhagen, Germany. The rectangular bar had a cross section of $110 \times 70 \mathrm{~mm}$ (extrusion ratio ER: 9). Specimens were machined with the load axis parallel to the extrusion direction (L).

The microstructure of AZ80 is shown in Figure 1. The average $\alpha$-grain size is about $30 \mu \mathrm{m}$. A discontinuous precipitation of $\mathrm{Mg}_{17} \mathrm{Al}_{12}$ is clearly seen by optical microscopy.

Tensile tests were performed at various temperatures on threaded cylindrical specimens having gage lengths and diameters of 20 and $4 \mathrm{~mm}$, respectively. The initial strain rate was $8.3 \cdot 10^{-4} \mathrm{~s}^{-1}$.

For fatigue testing, threaded circumferentially notched specimens (Fig. 2) with a geometrical notch factor of about $k_{\mathrm{t}}=3.4$ were machined. After machining, roughly $200 \mu \mathrm{m}$ were removed 
from the surface of the specimens by electrolytical polishing to ensure that any machining effect that could mask the results was absent. This electropolished condition (EP) is taken as reference to which shot peened conditions (SP) will be compared.

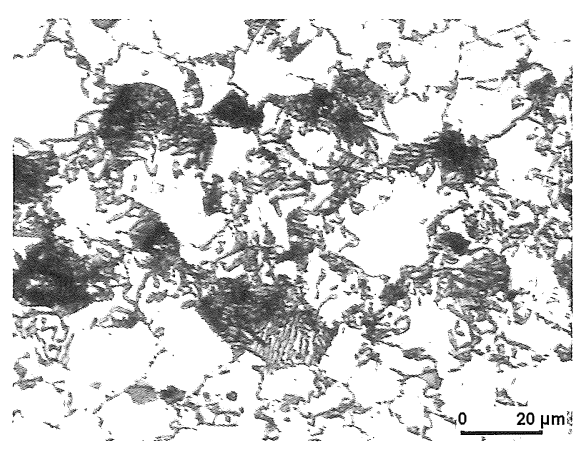

Figure 1: Microstructure of AZ80

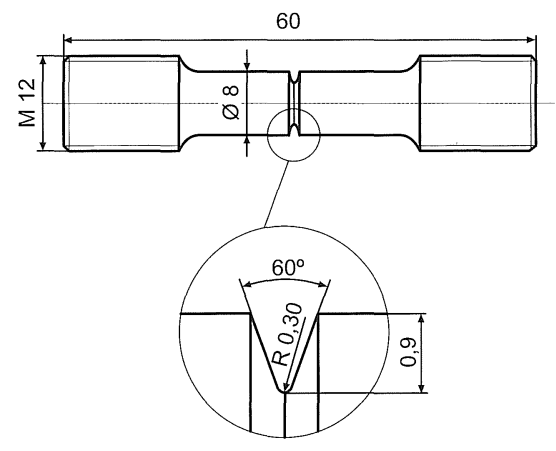

Figure 2: Geometry of fatigue specimens

Shot peening (SP) was performed with an injector type machine using spherically conditioned cut wire SCCW 14 ( $0.36 \mathrm{~mm}$ average shot size). Specimens were shot peened to full coverage using Almen intensities from 0.18 to $0.55 \mathrm{mmN}$. During shot peening, the surface of the specimens close to the notch was masked by an adhesive tape to ensure that the notch factor was not affected by removal of material from these regions. The exact value of the geometrical notch factor was calculated for each individual specimen by measuring the net diameter $\left(d_{n}\right)$, notch depth ( $t$ ) and notch root radius $(\rho)$ using the formula (1) for axial loading [6]:

$$
k_{\mathrm{t}}=1+\frac{1}{\sqrt{\frac{0.10}{\left(\frac{t}{\rho}\right)^{0.55}}+1.6\left[\frac{1+\frac{d_{\mathrm{n}}}{2 \rho}}{\frac{d_{\mathrm{n}}}{2 \rho} \sqrt{\frac{d_{\mathrm{n}}}{2 \rho}}}\right]^{2.5}+0.11 \frac{\frac{d_{\mathrm{n}}}{2 \rho}}{\left(\frac{d_{\mathrm{n}}}{2 \rho}+\frac{t}{\rho}\right)\left(\frac{t}{\rho}\right)^{1.5}}}}
$$

After shot peening, the change in surface layer properties was determined by roughness measurements through profilometry, microhardness-depth profiles and measurements of residual stresses by means of the incremental hole drilling method as described in detail elsewhere [7].

Axial fatigue tests were performed in fully reserved loading $(R=-1)$ using a resonance tester and frequencies of about 60 to $70 \mathrm{~Hz}$. These tests were done in an environmental chamber at temperatures ranging from -25 to $+50{ }^{\circ} \mathrm{C}$. 


\section{$4 \quad$ Results and Discussion}

Tensile properties at the various temperatures are summarized in Table 1. As seen in Figure 3, yield stress $\sigma_{0.2}$ and tensile strength UTS continuously decrease as the temperature increases while both uniform strain $\varepsilon_{\mathrm{u}}$ and fracture strain $\mathrm{El}$ increase.

Table 1: Tensile properties of AZ80 at various temperatures

\begin{tabular}{rlllrr}
\hline Temperature & $E$ & $\sigma_{0.2}$ & UTS & $e_{\mathrm{U}}$ & \multicolumn{1}{c}{$E l$} \\
\hline$\left[{ }^{\circ} \mathrm{C}\right]$ & {$[\mathrm{GPa}]$} & {$[\mathrm{MPa}]$} & {$[\mathrm{MPa}]$} & {$[\%]$} & {$[\%]$} \\
100 & 35 & 220 & 320 & 12.3 & 17.0 \\
50 & 46 & 240 & 330 & 7.8 & 9.3 \\
25 & 43 & 245 & 335 & 8.9 & 10.1 \\
0 & 45 & 255 & 340 & 8.8 & 9.1 \\
-10 & 45 & 260 & 340 & 6.9 & 7.0 \\
-25 & 49 & 280 & 360 & 7.2 & 7.3 \\
\hline
\end{tabular}

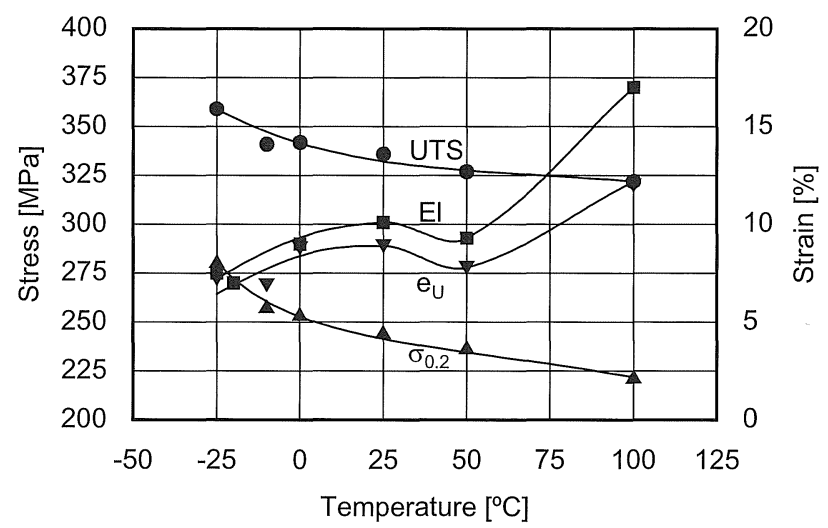

Figure 3: Tensile properties of AZ80 vs. test temperature

Shot peening markedly changes the surface topography as seen in Figure 4. With an increase in Almen intensity from 0.18 to $0.55 \mathrm{mmN}$, the surface roughness steadily increases.

Owing to marked work-hardening in AZ80, the near-surface microhardness significantly increases during shot peening (Fig. 5). Increasing the Almen intensity from 0.18 to $0.55 \mathrm{mmN}$ leads to greater depths of plastic deformation. Shot peening-induced residual stresses as determined by the hole drilling method are illustrated in Figure 6 . Shot peening to $0.18 \mathrm{mmN}$ Almen intensity leads to maximum residual compressive stresses at the surface, while peening to 0.55 $\mathrm{mmN}$ results in a marked drop of near-surface stresses (Fig. 6). For HCF testing, specimens were shot peened only to the low Almen intensity of $0.18 \mathrm{mmN}$. 

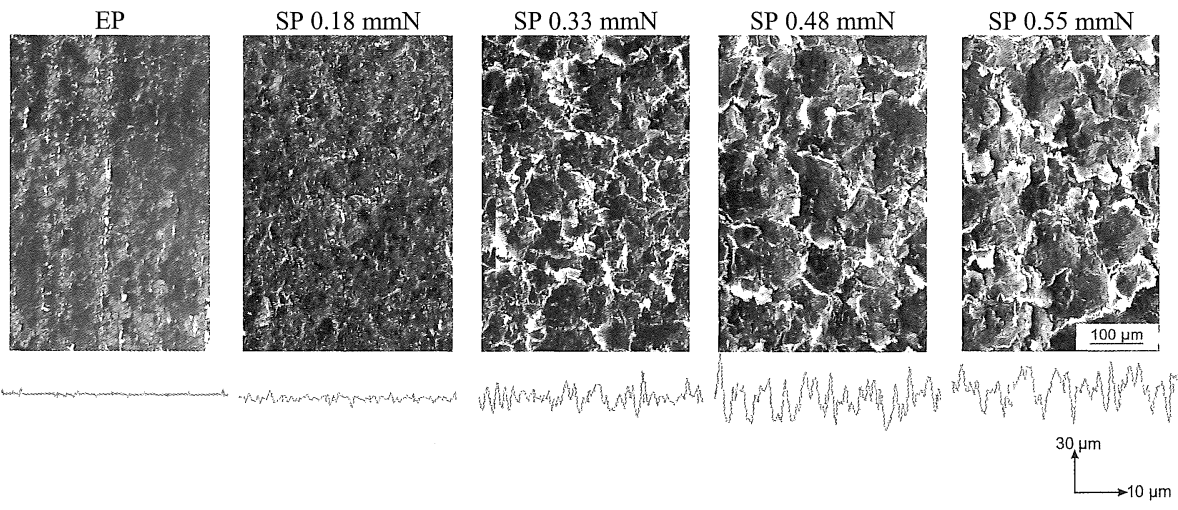

Figure 4: Surface topographies and roughness profiles after shot peening of AZ80

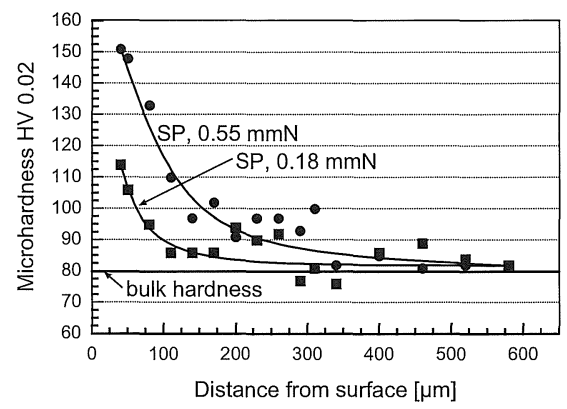

Figure 5: Microhardness-depth profiles after shot peening

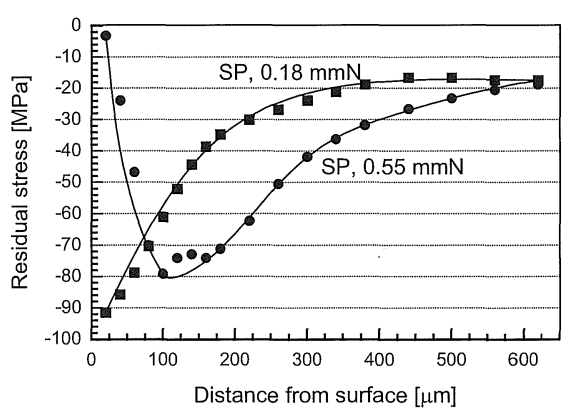

Figure 6: Residual stress-depth profiles after shot peening

The effect of test temperature on the HCF performance in fully reversed $(R=-1)$ axial loading of notched specimens of AZ80 is shown in Figure 7.

For the electropolished (EP) reference condition (Fig. 7a), the S-N curves at temperatures of $T=50,25$ and $-25{ }^{\circ} \mathrm{C}$ are quite similar and can be characterized in the HCF regime by a common scatterband. However, the HCF performance at the temperatures of $T=0{ }^{\circ} \mathrm{C}$ and $T=-10{ }^{\circ} \mathrm{C}$ is clearly inferior to the other temperatures tested. For example, the $10^{7}$ cycles fatigue strength of notched AZ80 is only $50 \mathrm{MPa}$ in terms of $\sigma_{\mathrm{a}} \cdot k_{\mathrm{t}}$ at a test temperature of $T=-10{ }^{\circ} \mathrm{C}$ whereas it is $175 \mathrm{MPa}$ at $T=50{ }^{\circ} \mathrm{C}$ (Fig. 7a).

After shot peening, the temperature dependent ranking of the HCF performance in AZ80 is quite the same (Fig. 7b). Again, the S-N curves at temperatures of $T=50{ }^{\circ} \mathrm{C}$ and $25{ }^{\circ} \mathrm{C}$ are similar while there is a pronounced drop in HCF performance at lower temperatures of $T=0{ }^{\circ} \mathrm{C}$ and $T=-10^{\circ} \mathrm{C}$.

From Figure 7, the $10^{7}$ cycles fatigue strengths of the electropolished references and the shot peened conditions were taken and replotted in Figure 8 vs. test temperature. Within the range of temperatures studied, the fatigue strength improvement caused by shot peening is independent 
of temperature and amounts to roughly $75 \mathrm{MPa}$ in terms of $\sigma_{\mathrm{a}} \cdot \mathrm{k}_{\mathrm{t}}$. This indicates that even at the highest tested temperature of $T=50{ }^{\circ} \mathrm{C}$, no significant thermal relaxation of the shot peeninginduced residual compressive stresses is likely to occur.

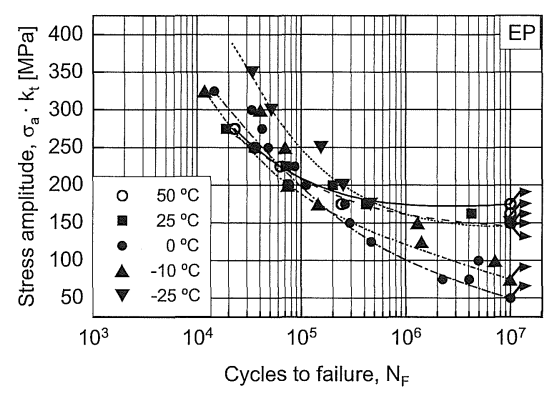

a) Condition EP

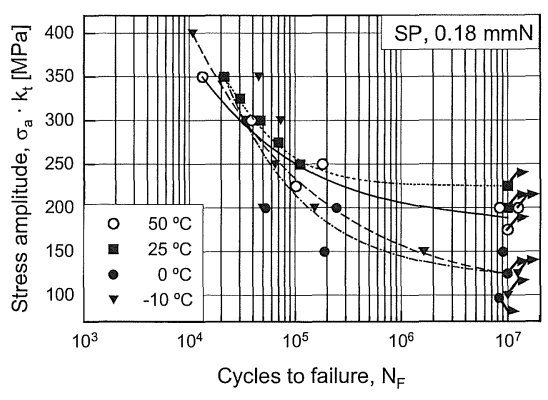

b) Condition SP

Figure 7: S-N curves in axial loading $(R=-1)$ of notched $\left(k_{\mathrm{t}}=3.4\right)$ specimens of AZ80, effect of test temperature

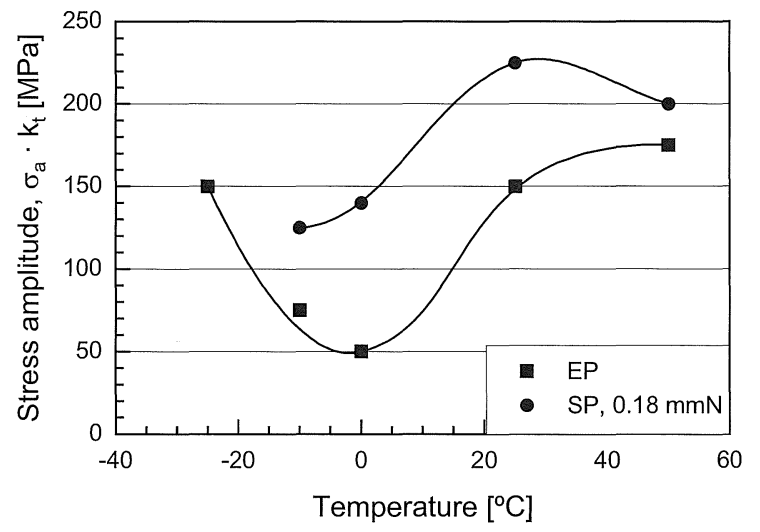

Figure 8: Fatigue strengths $(R=-1)$ of notched specimens of AZ80 vs. temperature

Presumably, the marked minimum in $10^{7}$ cycles fatigue strengths of both the electropolished and shot peened conditions at around $T=0{ }^{\circ} \mathrm{C}$ is due to environmental rather than mechanical aspects. The humidity of the lab air in the test chamber was found to be at a maximum at around $T=0{ }^{\circ} \mathrm{C}$. Thus, corrosion fatigue may play a significant role in fatigue of AZ80 at temperatures around $0{ }^{\circ} \mathrm{C}$.

Further work is needed to understand the comparatively poor fatigue performance of magnesium alloys at low temperatures. 


\section{Acknowledgements}

The authors gratefully acknowledge the support of this work by the Bundesministerium für Wirtschaft (BMWi) under contract 138/99. Thanks are also due to Ms. G. Rodenbeck for carrying out the residual stress measurements.

\section{References}

[1] T. K. Aune and H. Westengen, Magnesium Alloys and their Applications (Eds.: B. L. Mordike and F. Hehmann) DGM, 1992, 221.

[2] H. Friedrich and S. Schumann, Magnesium 2000 (Eds.: E. Aghion and D. Eliezer) MRI, $2000,9$.

[3] G. L. Song and A. Atrens, Advanced Engineering Materials, Wiley-VCH (1999), 11.

[4] C. Gerdes and G. Lütjering, Shot Peening (Ed.: H. O. Fuchs), American Shot Peening Society, Paramus, 1984, 175.

[5] L. Wagner, C. Gerdes and G. Lütjering, Titanium Science and Technology, DGM, 1985, 2147.

[6] W. Beitz and K.-H. Grote, Handbook for Mechanical Engineering, Springer, 2001, E 103 (in German).

[7] J. Lindemann, D. Roth-Fagaraseanu and L. Wagner, Shot Peening (Ed.: L. Wagner), Wiley-VCH, 2002, in press. 